\title{
Unidade de Esforço de Produção (UEP) como Método de Custeio: Implantação de Modelo em uma Indústria de Laticínios
}

\begin{abstract}
Daiane Cambruzzi
Pós-Graduação em andamento em Gestão pela Universidade Estadual do CentroOeste - UNICENTRO Rua Presidente Zacarias, 875. (CCSA/Unicentro). Guarapuava/PR. CEP: 85010-990 E-mail: daicambruzi@yahoo.com.br
\end{abstract}

Fábio Vianei Balen Pós-Graduação em andamento em Gestão Empresarial pela Universidade Estadual do

Centro-Oeste - UNICENTRO Rua Presidente Zacarias, 875. (CCSA/Unicentro). Guarapuava/PR. CEP: 85010-990 E-mail:jmorozini@unicentro.br

João Francisco Morozini Doutorado em andamento em Administração de Empresas pela Universidade Presbiteriana Mackenzie Professor da Universidade Estadual do Centro-Oeste - UNICENTRO Rua Presidente Zacarias, 875. (CCSA/Unicentro). Guarapuava/PR. CEP: 85010-990

E-mail:jmorozini@uol.com.br

\section{RESUMO}

O método UEP fundamenta-se na noção de esforço de produção, isto é, o esforço realizado por uma máquina funcionando, o esforço humano, o esforço dos capitais, o esforço da energia aplicada e outro direta ou indiretamente aplicados. Tal método propicia além do custo de transformação dos produtos, outros inúmeros subsídios de extrema utilidade na gestão industrial. $O$ objetivo deste artigo é evidenciar a aplicabilidade do método da unidade de esforço de produção - UEP na linha de produção de uma indústria de laticínios como método de custeio. Trata-se de um estudo de caso com abordagem quantitativa do problema. $A$ análise dos resultados permite constatar a eficiência do método no segmento industrial, mas, principalmente, evidenciar os passos para a sua implantação. Conclui-se que o método UEP descrito ao longo desse artigo revela ser um método bastante adequado como método de custeio.

Palavras-chave: UEP. Método de custeio. Laticínio.

Unity Effort of Production (UEP) as a Method of Costing: Implementation of the Model in a Dairy Industry 
Unidade de Esforço de Produção (UEP) como Método de Custeio: Implantação de Modelo em uma

Indústria de Laticínios

Daiane Cambruzzi, Fábio Vianei Balen, João Francisco Morozini

\section{ABSTRACT}

The UEP method is based on the notion of effort in production, that is, the effort made by a machine running, the human effort, the effort of the capital, effort and energy applied directly or indirectly applied. This method also provides the cost of processing of products, numerous other benefits of extreme usefulness in industrial management. This article aims to highlight the applicability of the method of the unity effort of production UEP in a production line for the dairy industry as a method of cost. This is a work through a case study, dealing with the problem and quantitative approach bibliography basement. After analyzing the results, it was possible to establish the efficiency of the method in the industrial sector, but mainly to show the steps deployment. It was concluded that the method described UEP work along that proves to be quite appropriate as a method of costing.

Key Words: UEP. Method of costing. Dairy Products.

\section{INTRODUÇÃO}

A competição enfrentada atualmente pelas empresas está muito acirrada, e com isso a sustentabilidade das mesmas no mercado é, sem duvida, uma tarefa muito difícil. Para a permanência das empresas no mercado, os gestores devem preocupar-se em identificar os custos dos produtos de uma forma clara e precisa, pois nem sempre os preços praticados junto ao mercado consumidor estão diretamente ligados aos seus verdadeiros custos de produção, mas seguem as condições econômicas impostas pelo mercado. Com isso, a falta de controle de custos de produção pode, muitas vezes, levar as empresas a praticar preços inferiores aos esforços e valores investidos na fabricação de seus produtos.

Vários métodos e sistemas de distribuição de custos foram propostos ao longo do tempo, com diferentes características e recomendados para diferentes situações. Um método de custeio de crescente implantação no Brasil nas últimas décadas é o método das Unidades de Esforço de Produção (UEPs). O método UEP se apresenta como uma alternativa bastante válida em relação aos métodos de custeio que tradicionalmente vêm sendo empregados. 
Unidade de Esforço de Produção (UEP) como Método de Custeio: Implantação de Modelo em uma Indústria de Laticínios

Daiane Cambruzzi, Fábio Vianei Balen, João Francisco Morozini

Tal método propicia, além do custo de transformação dos produtos, outros inúmeros subsídios de extrema utilidade na gestão industrial, na medida em que propicia a análise de cada etapa do processo produtivo e não somente o resultado final.

Este artigo tem como objetivo evidenciar a aplicabilidade do método da Unidade de Esforço de Produção - UEP na linha de produção de uma indústria de laticínios como método de custeio.

\section{FUNDAMENTAÇÃO TEÓRICA}

\subsection{Sistemas de Custeio}

A Contabilidade de custos gera suas informações baseadas no sistema de custeio utilizado pela entidade no decorrer de suas atividades. O sistema de custeio, que está sob a responsabilidade da Contabilidade de Custos, tem como finalidade, de acordo com Coronetti, Beuren e Souza (2003), relatar dados de diferentes fontes, tornando-os úteis à gestão, bem como indicar como os recursos de uma firma são consumidos por seus objetos de custeio.

Kaplan e Cooper (1998 apud MUNARETTO; DIEDRICH, 2005) descrevem os seguintes objetivos a serem alcançados pelos sistemas de custos: (a) possibilitar a avaliação dos estoques para relatórios financeiros e fiscais, alocando os custos de produção entre os produtos vendidos e em estoques; (b) proporcionar controle operacional, fornecendo informações para gerentes de produção sobre os recursos consumidos durante o período; e (c) apurar individualmente os custos dos produtos.

Bornia (2002) explica que o sistema de custeio deve estar em sintonia e adaptado ao sistema de gestão da empresa, possibilitando fornecer informações que levem a decisões corretas, diante do atual ambiente competitivo. Ainda de acordo com o autor, a análise de um sistema de custos pode ser efetuada sob duas formas: (1) analisando se o tipo de informação gerada é adequado às necessidades da empresa e quais seriam as informações importantes que deveriam ser fornecidas; e (2) levando em consideração a parte operacional do mesmo, ou seja, como os dados são processados para a obtenção das informações. 
Unidade de Esforço de Produção (UEP) como Método de Custeio: Implantação de Modelo em uma Indústria de Laticínios

Daiane Cambruzzi, Fábio Vianei Balen, João Francisco Morozini

Para Martins (2003), os sistemas também devem levar em consideração: a qualidade dos profissionais envolvidos na alimentação do processo; a necessidade de informação de que necessita o usuário final; a relação dos benefícios oferecidos pelo sistema e seu valor monetário.

Quando se apresenta adequado às necessidades da empresa, o sistema de custos determina quais dados serão processados e relatados sob a forma de informações e relatórios para a gestão, de modo a atender suas necessidades na tomada de decisões. Morais et al. (1986) afirmam que o sistema visa, principalmente, subsidiar o usuário com informações que contribuam para o exercício das funções de controle e planejamento. Portanto, o sistema procura disponibilizar aos usuários o maior número possível de informações, auxiliando-os na gestão de seus negócios.

Diversos são os sistemas de custeio que podem ser utilizados pelas empresas. Cada sistema de custeio tem características próprias, podendo numa mesma situação apresentar resultados diferentes. Cabe ao gestor de custos optar pelo sistema de custeio que melhor se adapte na estrutura física e operacional da empresa. Além disso, deve considerar aquele que mais pode contribuir na análise dos custos e dar suporte na busca de vantagens competitivas para a empresa. No entanto, como bem observa Martins (2003), nenhum sistema possui capacidade de solucionar todos os problemas, isso porque para que um sistema consiga atingir sua capacidade de funcionar como instrumento de administração, precisa desenvolver-se e aprimorar-se.

\subsection{Método de Unidade de Esforço de Produção - UEP}

\subsubsection{Origens do Método}

Conforme mencionam Allora e Allora (1995), a concepção básica do método UEP de unificar a medição da produção industrial por meio de uma única unidade de medida abstrata, vem de longa data.

O método UEP teve a sua origem na França por ocasião da Segunda Guerra Mundial, tendo o engenheiro francês Georges Perrin como precursor dos estudos realizados acerca desse método. De acordo com Allora e Allora (1995), Perrin considerava que se o método alemão RKW criava e utilizava uma unidade de medida 
Unidade de Esforço de Produção (UEP) como Método de Custeio: Implantação de Modelo em uma Indústria de Laticínios

Daiane Cambruzzi, Fábio Vianei Balen, João Francisco Morozini

abstrata para medir a produção diversificada, numa seção homogênea, deveria haver um meio de criar uma unidade de medida para medir a produção diversificada, não numa seção, mas na fábrica inteira. Dos estudos que realizou, Perrin desenvolveu sua própria unidade de medida da produção a qual denominou de "GP", iniciais de Georges Perrin.

$\mathrm{Na}$ França, o método caiu em esquecimento após o falecimento de Perrin. Segundo Bornia (2002), um discípulo de Perrin, Franz Allora, modificou o método GP, criando o que denominou método de UP`s, ou método das UEP`s. No início da década de 1960 trouxe o método para o Brasil.

Em 1978, passou a implantar este método de custeio em empresas das regiões de Blumenau e Joinville, ambas localizadas no Estado de Santa Catarina, quando foi criada uma empresa de consultoria em Blumenau, cuja atividade baseava-se na implantação deste método de custos, chegando a implantá-lo em cerca de 30 empresas daquele Estado.

A partir de meados da década de 1980 um grupo de pesquisadores da Universidade Federal de Santa Catarina e, posteriormente, da Universidade Federal do Rio Grande do Sul, estudaram e aprimoraram o método, sendo, desta forma, divulgado por meio de trabalhos científicos e congressos e implantado em diversas empresas da Região Sul do Brasil (WERNKE; MORAES; CARDOSO, 2004).

Conforme Wernke, Moraes e Cardoso (2004), o método UEP atualmente vem sendo utilizado por mais de uma centena de empresas, principalmente nos Estados do Paraná, Santa Catarina e Rio Grande do Sul.

\subsubsection{Conceitos e Principais Características do Método UEP}

De acordo com Allora e Allora (1995), não existem informações ou decisões a tomar que não devam estar diretamente relacionadas ao conceito de produção. Quando as empresas possuem vários procedimentos sendo executados ao longo da linha de produção, tendo processo fabril complexo e uma produção diversificada, maiores são os problemas relativos à gestão das atividades no ambiente fabril, principalmente no que se refere à alocação de custos indiretos aos itens produzidos. 
Unidade de Esforço de Produção (UEP) como Método de Custeio: Implantação de Modelo em uma Indústria de Laticínios

Daiane Cambruzzi, Fábio Vianei Balen, João Francisco Morozini

Para tais situações há a necessidade de empregar metodologias de custeamento mais aprimoradas, como é o caso do método das Unidades de Esforço de Produção (UEP). Conforme Bornia (2008), pelo método da UEP há uma simplificação da forma de cálculo da produção do período, mediante a utilização de uma unidade de medida comum a todos os produtos (e processos) da empresa.

O método da UEP baseia-se na unificação da produção para simplificar o processo de controle de gestão. Conforme Bornia (2002), unificar a produção significa encontrar uma unidade de medida comum a toda a produção da empresa, onde o trabalho realizado pelas operações produtivas na transformação da matéria-prima em produto acabado, centra nos esforços de produção da empresa.

A determinação de uma unidade de medida comum a todos os produtos e processos da empresa, a chamada UEP, conforme Bornia (2002), é uma medida que indicará, de forma quantitativa, o esforço despendido na transformação da matériaprima em produto acabado.

Assim, a mão-de-obra (direta e indireta), a energia elétrica utilizada para mover as máquinas, os materiais de consumo necessários para por em funcionamento a fábrica, a manutenção do equipamento, o controle de qualidade, enfim, tudo o que se relaciona com a produção da empresa gera esforços de produção. No entanto, Bornia (2004) ressalva que as matérias primas e as despesas não são incluídas no processo de transformação da matéria-prima em produtos acabados.

No método UEP, Yoshitake et al. (2003) assinala que os custos unitários dos produtos são resumidos em custos das matérias primas consumidas e custos de transformação. Quanto às matérias primas consumidas, o custeio de cada produto é obtido facilmente. Logo, o método preocupa-se basicamente com os custos de transformação. Estes são conhecidos também como custos de conversão ou custos de agregação e representam o esforço agregado pela empresa na obtenção do produto. São todos os custos de produção, exceto matérias-primas, os componentes adquiridos prontos e as embalagens compradas.

Para o método em estudo, os focos concentradores dos esforços de produção das empresas são todas as atividades diretamente envolvidas na fabricação dos 
Unidade de Esforço de Produção (UEP) como Método de Custeio: Implantação de Modelo em uma Indústria de Laticínios

Daiane Cambruzzi, Fábio Vianei Balen, João Francisco Morozini

produtos. Os esforços das atividades auxiliares são repassados às atividades produtivas e, daí, aos produtos.

Conforme Coral (1996, p.16), "o método de custeio através da UEP possibilita transformar uma empresa multiprodutora em monoprodutora através da utilização de uma unidade de medida padronizada".

Segundo Diniz et al. (2004), cada produto, por mais numeroso e diversificado que seja, poderá ser medido pela quantidade de esforço que foi necessário para fabricá-lo, o qual foi concebido pela passagem por diversos postos operativos que, por sua vez, realizam tal esforço. A empresa é vista como agregadora de valor através dos seus postos operativos no intuito de transformar as matérias primas em produtos acabados.

A técnica UEP não trabalha com os conceitos de custos fixos e variáveis. Tal divisão, segundo Allora e Allora (1995), serve somente para finalidades contábeis, não tendo aplicações práticas. Diniz et al. (2004) relatam que as UP's ou UEP's, mantêm-se constantes por longo tempo. Recálculos de revisão feitos depois de cinco ou mais anos em várias empresas, onde houve notáveis ampliações em locais, pessoas e máquinas, apresentaram variações insignificantes nas UEP's, confirmando paralelamente sua constância no tempo.

\subsubsection{Enfoque do Método UEP: Os Esforços de Produção}

Sakamoto (2003, p.4) afirma que o método UEP fundamenta-se na "noção de esforço de produção, isto é, o esforço realizado por uma máquina funcionando, o esforço humano, o esforço dos capitais, o esforço da energia aplicada e outros direta ou indiretamente aplicados". Considera, então, que os produtos são avaliados pela quantidade de esforços que requerem para serem fabricados, em cada setor produtivo ou posto operativo.

O método UEP parte do princípio que na transformação da matéria-prima a empresa agrega valor através de diversos esforços. A partir daí, busca-se medir os esforços de produção necessários para se obter uma unidade de produto, já que tais 
Unidade de Esforço de Produção (UEP) como Método de Custeio: Implantação de Modelo em uma Indústria de Laticínios

Daiane Cambruzzi, Fábio Vianei Balen, João Francisco Morozini

esforços determinam o custo de processamento da matéria-prima em produto (PEREIRA; REBELATO; TACHIBANA, 2000).

A noção do Esforço de Produção está diretamente associada aos diversos esforços imprescindíveis para a fabricação dos produtos, quais sejam:

Os Esforços Salariais (representados pelos salários, provisões e encargos sociais que fazem parte do total de remunerações de um trabalhador); o Esforço Material (representados pelos materiais de consumos e ferramentas consumidos gastas pelo posto operativo no processo produtivo); o Esforço de Capital (aqui representado pelo valor das máquinas e equipamentos, transformado em depreciação); os Esforços de Utilidades (compreende vapor, gás, ar comprimido); o Esforço de Energia Elétrica (aqui representado pelo valor da energia elétrica consumida pela potência elétrica do posto operativo), além de todos os esforços indiretos como manutenção, ferramentaria e outros.

Além disso, essa noção de esforço de produção possui uma característica que Ihe confere uma grande força, que é a homogeneidade. A característica da homogeneidade permite que se possa afirmar que quaisquer que sejam os produtos fabricados e seus respectivos processos de fabricação, a produção destes produtos necessita de esforços de produção de mesma natureza, embora de diferente intensidade, e é exatamente porque os esforços de produção são de mesma natureza que estes podem ser adicionados, qualquer que seja o produto considerado na fábrica.

Assim, produtos diferentes que não são comparáveis e adicionáveis entre si, poderão sê-lo através da noção de Esforço de Produção. O Esforço de Produção total da fábrica pode, então, ser concebido como a soma dos esforços de produção de cada um dos produtos.

Wernke e Lembeck (2008) citam que pelo método UEP os custos unitários dos produtos são resumidos em custos das matérias-primas consumidas e custos de transformação.

Quanto às matérias-primas consumidas, o custeio de cada produto é obtido facilmente nas fichas técnicas individuais dos produtos. Assim, o método UEP preocupa-se basicamente com os custos de transformação que, conforme consta da 
Unidade de Esforço de Produção (UEP) como Método de Custeio: Implantação de Modelo em uma Indústria de Laticínios

Daiane Cambruzzi, Fábio Vianei Balen, João Francisco Morozini

obra do Sakamoto (2003), estes são conhecidos também como custos de conversão ou custos de agregação e representam o esforço realizado pela empresa para obtenção do produto. São todos os custos de produção, exceto as matérias primas, os componentes adquiridos prontos e as embalagens compradas.

\subsubsection{Os Princípios Fundamentais do Método das UEP's}

De acordo com Fernandes (2003), para a construção do Método das UEPs se faz necessário sedimentar as idéias básicas que lhes dão sustentação, isto é, nos dois princípios fundamentais estabelecidos por Perrin em 1971: (a) o princípio das relações constantes; e (b) o princípio das estratificações. Em decorrência do estudo destes dois princípios, Kliemann Neto (1995) desenvolveu um terceiro princípio que é o princípio do valor agregado.

O princípio do valor agregado é o princípio mais geral do Método das UEPs. Considera-se que o produto de uma fábrica resulta do trabalho que ela realiza sobre as matérias primas, e repercute no valor que ela agrega a essas matérias primas durante 0 processo de fabricação (KLIEMANN NETO 1995 apud FARIAS; LEMBECK, 2005).

De acordo com este princípio, o método das UEPs encara as matérias primas como meros "objetos de trabalho". A unificação e o controle da produção serão feitas em função do esforço despendidos pelos diversos postos operativos para a transformação das matérias primas em produtos acabados.

Ao tratar do princípio das relações constantes Perrin (1971 apud FERNANDES, 2003), considera que independente de quaisquer que sejam os preços unitários, os esforços de produção levados a cabo nas diversas operações elementares teóricas do trabalho realizado em uma fábrica, acabam tendo relações constantes entre si no tempo.

Esse princípio considera que a relação entre os potenciais produtivos de dois postos operativos se mantém constante no decorrer do tempo. Um posto operativo rigorosamente definido possui certo potencial produtivo, o qual não variará no tempo se as características do posto permanecerem as mesmas, dado que o potencial produtivo 
Unidade de Esforço de Produção (UEP) como Método de Custeio: Implantação de Modelo em uma Indústria de Laticínios

Daiane Cambruzzi, Fábio Vianei Balen, João Francisco Morozini

representa a capacidade do posto operativo efetuar o trabalho. Somente deverão ocorrer mudanças quando ocorrer alterações na estrutura de produção da fábrica.

Perrin (1971 apud FERNANDES, 2003) menciona que o princípio das estratificações considera que o grau de exatidão de um custo cresce com cada item de despesas ou gastos considerados como despesas imputáveis. Pode-se dizer que o máximo de precisão possível que se pode alcançar ocorre quando todos os itens de gastos fabris puderem ser passíveis de serem atribuídos diretamente aos postos operativos, ou seja, se todas as despesas puderem ser imputadas haverá uma melhoria na precisão dos custos, pois se estará distribuindo melhor as despesas aos postos operativos. Em outras palavras, o que o princípio das estratificações diz é que todas as despesas que são consideradas como não imputáveis são as causas da inexatidão nos preços de custo dos produtos.

\section{METOLOGIA}

No que se refere aos aspectos metodológicos, este trabalho está alicerçado numa pesquisa bibliográfica, seguida de um estudo de caso. O estudo de caso compreende um "estudo profundo e exaustivo de um ou poucos objetivos, de maneira que permita seu amplo e detalhado conhecimento" (GIL, 2002, p.54).

Quanto à forma de abordagem do problema, a pesquisa é classificada como quantitativa, pois de acordo com Gil (2002) a pesquisa quantitativa existe quando a resposta a um problema exige a utilização de quantidades físicas e valores.

Com relação aos métodos empregados para a coleta de dados, com a finalidade de atingir os objetivos propostos nesse trabalho, foram realizados os seguintes procedimentos:

Para implantação deste método, segundo Wernke (2005, p.63), é necessária a realização de oito etapas, que são: a) Divisão da fábrica em postos operativos; b) Determinação dos índices de custos horários por posto operativo FIPO (ou o Custo/hora por posto operativo); c) Obtenção dos tempos de passagem dos produtos pelos postos operativos; d) Escolha do produto-base; e) Cálculo dos potenciais produtivos (UEP/hora) de cada posto operativo; f) Definição dos equivalentes dos produtos em 
Unidade de Esforço de Produção (UEP) como Método de Custeio: Implantação de Modelo em uma Indústria de Laticínios

Daiane Cambruzzi, Fábio Vianei Balen, João Francisco Morozini

UEP (valor em UEP do produto); g) Mensuração da produção total em UEP; e h) Cálculo dos custos de transformação.

Após isso, o primeiro procedimento a ser realizado consiste em dividir a fábrica em postos operativos (PO), locais onde são executadas as operações relativas à transformação dos produtos. Essas operações caracterizam-se por serem utilizadas de forma semelhante pelos produtos que passam pelo posto operativo.

Segundo Bornia (1995), um posto operativo é constituído por operações de transformação homogêneas, ou seja, é um conjunto formado por uma ou mais operações produtivas elementares, as quais apresentam características semelhantes para todos os produtos que passam pelo $\mathrm{PO}$, diferindo no tempo de passagem por ele.

Um posto operativo poderá ser definido como sendo uma Máquina que efetuará uma operação elementar de trabalho ou um agrupamento de máquinas com vários operários que efetuaram uma ou mais operações. É de grande importância uma correta escolha destas operações elementares que constituem um posto operativo, pois isto refletirá diretamente na precisão dos potenciais produtivos dos mesmos.

Uma máquina pode comportar dois ou mais PO's, caso as operações efetuadas nos produtos sejam significativamente diferentes. Da mesma maneira, um PO pode englobar duas ou mais máquinas, se as operações nos produtos forem praticamente homogêneas.

Na sequência apura-se o cálculo do custo/hora (em \$) por posto operativo. Essa segunda etapa do processo de implementação do método de custeio UEP constitui-se na determinação dos índices de custos horários por posto operativo (custo/hora em \$). Bornia (2002, p.145) assinala que "estes índices de custos são calculados tecnicamente, de acordo com o efetivo dispêndio de insumos por parte dos postos operativos em funcionamento, com exceção da matéria-prima e despesas de estrutura".

O custo-hora é obtido dividindo-se o total (em \$) mensal de custos de transformação do posto operativo pelo número previsto de horas trabalhadas no período, sendo que existe uma gama de itens referentes ao custo de transformação que deve ser considerada. Tanto Antunes Júnior (1988) como larozinski Neto (1989) sugerem um roteiro que contém os principais itens que poderão ser utilizados para 
Unidade de Esforço de Produção (UEP) como Método de Custeio: Implantação de Modelo em uma Indústria de Laticínios

Daiane Cambruzzi, Fábio Vianei Balen, João Francisco Morozini

facilitar os cálculos. Diniz et al. (2004) acrescenta que se esta relação for considerada insuficiente, deverá ser efetuado um estudo mais minucioso verificando-se os benefícios advindos à implementação do método. As principais contas que são utilizadas para a obtenção do foto-índice são: a) Mão-de-obra Direta; b) Mão-de-obra Indireta; c) Encargos e Benefícios Sociais; d) Depreciação Técnica ou Extracontábil; e) Material de Consumo Específico; f) Material de Consumo Geral; g) Energia Elétrica; h) Obtenção dos Tempos de Passagem dos Produtos pelos Postos Operativos; i) Escolha do produto base; j) Determinação dos Equivalentes dos Produtos em UEP (valor em UEP do produto); k) Mensuração da Produção Total em UEP; e I) Cálculo dos Custos de Transformação. A partir destes elementos foi realizada a divisão da fábrica em postos operativos. Após essa divisão foram realizados os cálculos.

\section{RESULTADOS}

Esse trabalho foi realizado junto à empresa aqui denominada como Laticínio Modelo Ltda., que é uma empresa familiar localizada no interior do Paraná. O leite, principal matéria prima utilizada pelo laticínio, é proveniente do município onde se localiza a empresa, assim como também de municípios da região.

A empresa processa cerca de 15.000 litros de leite ao dia. Produz diversos produtos, a saber: queijo mussarela, queijo prato, queijo provolone, queijo minas, manteiga, creme de leite e ricota, sendo o primeiro produto citado o de maior produção na empresa. Sua produção se situa entre $45.000 \mathrm{~kg}$ a $50.000 \mathrm{~kg}$ de queijo ao mês, sendo que essa produção varia de acordo com o volume de matéria-prima processada. Após a análise da realidade vivenciada pela empresa, foram detectados alguns pontos que merecem destaque.

A empresa analisa os custos de seus produtos por intermédio do preço de compra da matéria-prima e através de um cálculo superficial do restante dos outros gastos envolvidos na produção e do lucro desejado. Observa-se que não são computados os insumos relevantes e necessários para a execução de suas atividades, tais como: salário dos funcionários, consumo de energia elétrica, depreciação de equipamentos utilizados na produção. 
Unidade de Esforço de Produção (UEP) como Método de Custeio: Implantação de Modelo em uma Indústria de Laticínios

Daiane Cambruzzi, Fábio Vianei Balen, João Francisco Morozini

Dentre os vários produtos que a empresa fabrica, o item escolhido para estudo neste trabalho foi o queijo mussarela, em virtude de ser o de maior produção e passar pelos principais postos operativos da empresa. A Figura 1 representa a estrutura da empresa e seu processo produtivo, com a divisão da linha de produção em postos operativos $(\mathrm{P})$.

Nas Tabelas 1 a 8 encontram-se dispostos os principais resultados alcançados nesse estudo.

Tabela 1 - Montagem do Fipo - Foto Índice dos Postos Operativos

\begin{tabular}{|c|c|c|}
\hline Código & Postos Operativos & $\mathbf{N}^{\circ}$ de Equipamentos \\
\hline P 01 & Armazenagem e Análise do Leite & 5 \\
\hline P 02 & Pasteurização, Padronização e Coagulação. & 5 \\
\hline P 03 & Prensa & 1 \\
\hline P 04 & Picagem, Filação e Moldagem & 2 \\
\hline P 05 & Tanque de água gelada & 1 \\
\hline P 06 & Descanso e Salmoura & 1 \\
\hline P 07 & Secagem & 1 \\
\hline P 08 & Embalagem e Armazenagem & 3 \\
\hline
\end{tabular}




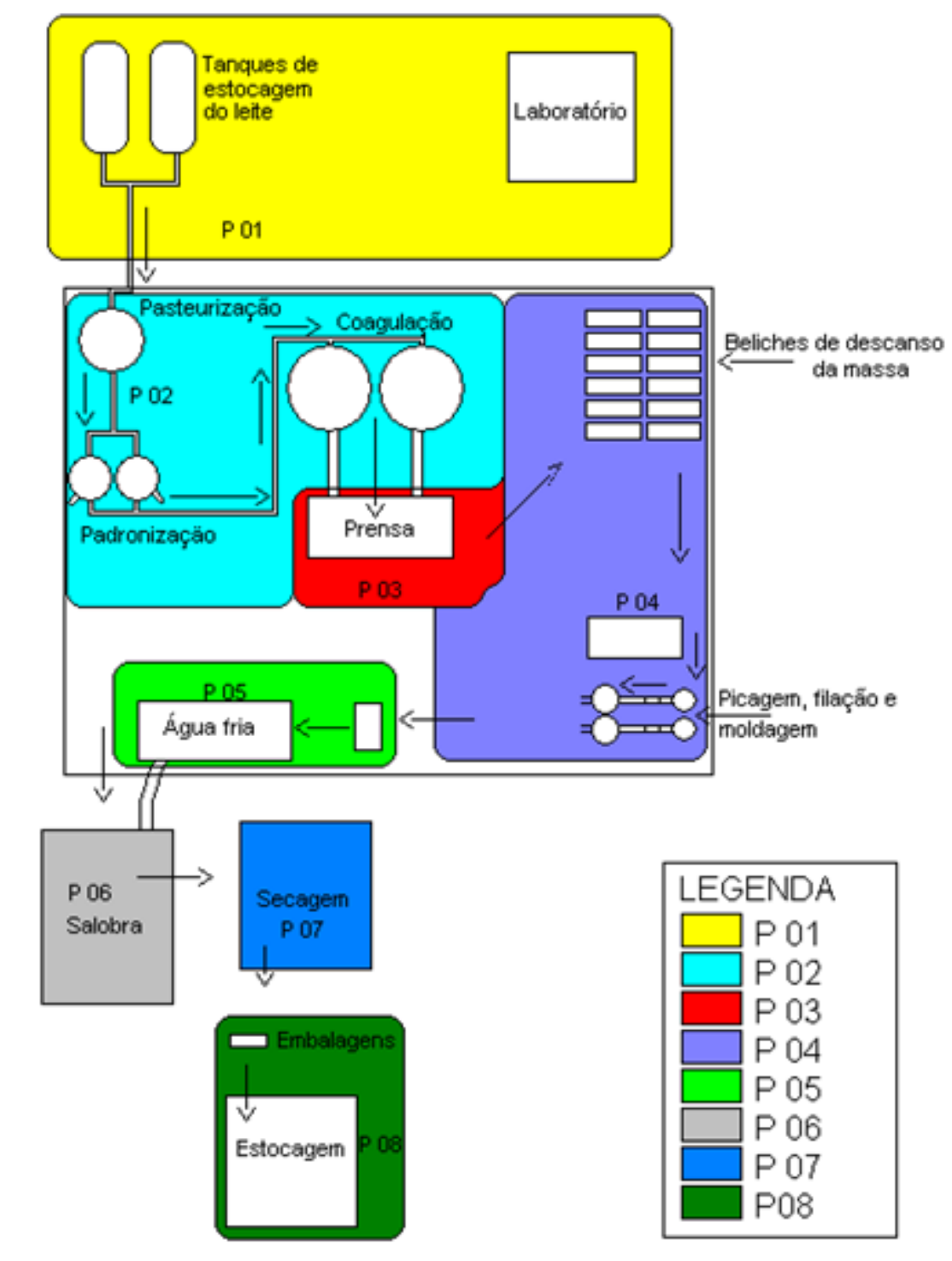

Figura 1 - Processo de produção

A primeira etapa de implementação do método UEP consiste na divisão da empresa em postos operativos. Na Tabela 1 é apresentada a forma como a empresa está dividida. Os postos operativos estão inseridos conforme a ordem de passagem de cada produto. Observa-se que alguns postos operativos foram formados a partir de um agrupamento de operações semelhantes enquanto que outros a partir de uma única atividade. A tabela também apresenta a quantidade de equipamentos que cada posto operativo possui. 
Unidade de Esforço de Produção (UEP) como Método de Custeio: Implantação de Modelo em uma Indústria de Laticínios

Daiane Cambruzzi, Fábio Vianei Balen, João Francisco Morozini

$\mathrm{Na}$ Tabela 2 são evidenciados os custos de transformação referentes a cada posto operativo.

Tabela 2 - Custos Totais dos Postos Operativos

\begin{tabular}{|c|c|c|c|c|c|c|c|}
\hline Código & MOD & Depreciação & Energia & Mat. Cons. & Manutenção & Vapor & $\begin{array}{c}\text { Gastos } \\
\text { Totais }\end{array}$ \\
\hline P 01 & 18,95 & 15,07 & 1,37 & 57,50 & - & - & 92,89 \\
\hline P 02 & 73,01 & 55,71 & 3,28 & 12,50 & - & 69,50 & 213,99 \\
\hline P 03 & 25,52 & 0,91 & 0,28 & - & - & - & 26,72 \\
\hline P 04 & 152,61 & 18,26 & 3,79 & - & - & 86,87 & 261,53 \\
\hline P 05 & 19,33 & 0,55 & 0,00 & 30,00 & - & - & 49,88 \\
\hline P 06 & 30,32 & 1,83 & 62,82 & 52,50 & 13,70 & - & 161,17 \\
\hline P 07 & 15,16 & 1,83 & 31,41 & - & - & - & 48,40 \\
\hline P 08 & 30,32 & 1,83 & 31,41 & - & - & 17,37 & 80,93 \\
\hline TOTAL & \multicolumn{7}{|l}{} \\
\hline
\end{tabular}

Para a determinação do valor da mão-de-obra, foi analisado cada posto operativo e a partir da constatação do envolvimento de cada funcionário com o posto foram realizados os cálculos, sendo o que o custo foi determinado com base na soma dos salários e encargos sociais dos funcionários que trabalham em cada posto operativo (PO). Na seqüência, o montante foi dividido pela quantidade de horas trabalhadas no mês.

Para o cálculo do valor da depreciação, como a empresa não dispunha de nenhum controle que informasse o valor da depreciação contábil, optou-se por calculála por meio da divisão do valor (em $\mathrm{R} \$$ ) das máquinas e equipamentos utilizados na produção pela expectativa de vida útil dos mesmos.

Com relação à Energia Elétrica, o valor mensal de cada posto operativo foi determinado de acordo com o consumo de cada máquina e equipamento utilizado na linha de produção. Para determinar tais consumos foram coletados dados como a potência de cada equipamento, em seguida realizado o cálculo da quantidade de kw gastos em cada um durante o dia. Para o cálculo da energia elétrica foi utilizada a seguinte fórmula:

$$
k W h=P^{*} t
$$


Unidade de Esforço de Produção (UEP) como Método de Custeio: Implantação de Modelo em uma Indústria de Laticínios

Daiane Cambruzzi, Fábio Vianei Balen, João Francisco Morozini

onde:

$\mathrm{P}=$ potência do equipamento em $\mathrm{KW}$ e

$\mathrm{t}=\mathrm{o}$ tempo de utilização do equipamento.

Como na maior parte dos motores a potência é em Watts, houve a necessidade de converter para KW, ou seja, dividir a potência em Watts por 1000 . No caso de motores com potência em $\mathrm{Hp}$ foi aplicada a seguinte fórmula: $W=\mathrm{Hp} \times 7,46$

$\mathrm{Na}$ indústria foram medidos o tempo de funcionamento de cada motor e a potência de cada um deles. Após, foi realizado o cálculo para a obtenção da energia consumida por motor, em seguida multiplicada pelo custo do KW cobrado.

Custos referentes ao material de consumo: no $1^{\circ}$ posto estão incluídas as despesas com análise laboratorial; no $2^{\circ}$ posto são gastos laboratoriais para análise do leite coagulado; no $5^{\circ}$ posto foi considerada a água utilizada para o resfriamento da massa do queijo já contido em fôrmas; e no $6^{\circ}$ posto estão incluídos o sal e a água utilizada para a salga do queijo. A manutenção refere-se à troca de placas da câmara fria que é utilizada para a salga do queijo.

Para o cálculo do vapor foram incluídos o custo de aquisição da lenha e o salário e encargos do funcionário que trabalhou na caldeira. Em seguida foi realizado o cálculo do consumo de cada posto operativo.

A Tabela 3 apresenta o custo/hora de todos os postos operativos da empresa.

Tabela 3 - Custo Hora dos Postos Operativos

\begin{tabular}{|c|c|c|c|}
\hline Código & Gastos Totais R\$ & Horas Trabalhadas & Custo Hora (R\$) \\
\hline P 01 & 92,89 & 5,00 & 18,58 \\
\hline P 02 & 213,99 & 8,00 & 26,75 \\
\hline P 03 & 26,72 & 3,37 & 7,94 \\
\hline P 04 & 261,53 & 8,00 & 32,69 \\
\hline P 05 & 49,88 & 2,55 & 19,56 \\
\hline P 06 & 161,17 & 4,00 & 40,29 \\
\hline P 07 & 48,40 & 2,00 & 24,20 \\
\hline P 08 & 80,93 & 4,00 & 20,23 \\
\hline
\end{tabular}


Unidade de Esforço de Produção (UEP) como Método de Custeio: Implantação de Modelo em uma Indústria de Laticínios

Daiane Cambruzzi, Fábio Vianei Balen, João Francisco Morozini

Após a verificação dos custos de cada processo, foram constatados os tempos de trabalho de cada posto operativo referente ao período de um dia. Em seguida, foram divididos os gastos totais de produção de cada posto operativo (Tabela 2) pela quantidade de horas trabalhadas, encontrando-se o custo/hora (em $\mathrm{R} \$$ ) de cada posto operativo (Tabela 4).

$\mathrm{Na}$ terceira etapa de implementação do método UEP requer-se o conhecimento dos tempos que os produtos levam para passar em cada posto operativo. Esta etapa é considerada como uma das mais importantes quando da aplicação do método UEP, isso porque, de acordo com Werneck (2005, p.65) "[...] erros cometidos nesse ponto influenciam todas as fases posteriores".

Tabela 4 - Custo do Produto Base

\begin{tabular}{|c|c|c|c|}
\hline Código & Custo Hora (R\$) & $\begin{array}{c}\text { Tempo de } \\
\text { Passagem }\end{array}$ & Custo do Prod. Base \\
\hline P 01 & 18,58 & 0,00438 & 0,0813 \\
\hline P 02 & 26,75 & 0,00701 & 0,1874 \\
\hline P 03 & 7,94 & 0,00295 & 0,0234 \\
\hline P 04 & 32,69 & 0,00701 & 0,2290 \\
\hline P 05 & 19,56 & 0,00223 & 0,0437 \\
\hline P 06 & 40,29 & 0,00350 & 0,1411 \\
\hline P 07 & 24,20 & 0,00175 & 0,0424 \\
\hline P 08 & 20,23 & 0,00350 & 0,0709 \\
\hline TOTAL & \multicolumn{3}{|c|}{} \\
\hline
\end{tabular}

O Quadro anterior apresenta os tempos de passagem do produto em estudo pelos vários postos operativos da empresa, bem como o custo do produto base. Foi multiplicado o custo hora de cada posto pelo tempo de passagem do produto pelo posto operativo, e dessa forma foi encontrado o custo total de passagem do produto pelos postos operativos.

Nesta etapa foram realizados os cálculos dos potenciais produtivos dos postos operativos (PO), a partir da divisão do custo hora de cada posto pelo custo do produto base, encontrando-se assim a capacidade de produção em UEPs por hora de cada (PO). 
Unidade de Esforço de Produção (UEP) como Método de Custeio: Implantação de Modelo em uma Indústria de Laticínios

Daiane Cambruzzi, Fábio Vianei Balen, João Francisco Morozini

A Tabela 5 apresenta o valor dos potenciais produtivos referentes a cada posto operativo (PO) da empresa.

O valor total significa o máximo de unidades concluídas que cada posto operativo consegue fazer por hora. Por exemplo, o posto operativo P01 consegue produzir 22,68 UEPs por hora, enquanto o posto operativo P02 consegue produzir 32,65 UEP por hora.

Tabela 5 - Potenciais Produtivos (UEP/Hora) dos Postos Operativos

\begin{tabular}{|c|c|c|c|}
\hline Código & Custo Hora PO & Custo Prod. Base & UEP/Hora \\
\hline P 01 & 18,58 & 0,8192 & 22,68 \\
\hline P 02 & 26,75 & 0,8192 & 32,65 \\
\hline P 03 & 7,94 & 0,8192 & 9,69 \\
\hline P 04 & 32,69 & 0,8192 & 39,91 \\
\hline P 05 & 19,56 & 0,8192 & 23,88 \\
\hline P 06 & 40,29 & 0,8192 & 49,19 \\
\hline P 07 & 24,20 & 0,8192 & 29,54 \\
\hline P 08 & 20,23 & 0,8192 & 24,70 \\
\hline TOTAL & \multicolumn{3}{|l}{} \\
\hline
\end{tabular}

Tabela 6 - Equivalente do Produto em UEP

\begin{tabular}{|c|c|c|c|}
\hline Código & UEP/Hora & $\begin{array}{c}\text { Tempo de } \\
\text { Passagem }\end{array}$ & Equivalente \\
\hline P 01 & 22,68 & 0,00438 & 0,09929 \\
\hline P 02 & 32,65 & 0,00701 & 0,22875 \\
\hline P 03 & 9,69 & 0,00295 & 0,02856 \\
\hline P 04 & 39,91 & 0,00701 & 0,27956 \\
\hline P 05 & 23,88 & 0,00223 & 0,05332 \\
\hline P 06 & 49,19 & 0,00350 & 0,17228 \\
\hline P 07 & 29,54 & 0,00175 & 0,05173 \\
\hline P 08 & 24,70 & 0,00350 & 0,08651 \\
\hline TOTAL & \multicolumn{3}{|l}{} \\
\hline
\end{tabular}

$\mathrm{Na}$ etapa seguinte foram determinados os equivalentes dos produtos em UEP. Essa determinação acontece, de acordo com Wernke e Lembeck (2008, p.28), "com a absorção, por parte do produto, do potencial produtivo de cada posto operativo (PO) ". Isso quer dizer que de acordo com o tempo de passagem do produto pelo posto operativo este vai consumir parte do potencial de produção do posto. Os equivalentes 
Unidade de Esforço de Produção (UEP) como Método de Custeio: Implantação de Modelo em uma Indústria de Laticínios

Daiane Cambruzzi, Fábio Vianei Balen, João Francisco Morozini

de produção apresentados na Tabela 6 identificam as UEPs consumidas pelo produto durante a passagem pelos postos operativos. Para a realização do cálculo foram multiplicadas as UEP/Hora pelo tempo de passagem por cada posto operativo.

$\mathrm{Na}$ Tabela 7 é apresentada a mensuração da produção da indústria em UEPs referentes a um dia de produção. Esse valor foi obtido através da multiplicação da quantidade produzida em um dia do produto, nesse caso o queijo mussarela, pelo equivalente do produto em UEP.

Tabela 7 - Produção Total em UEP

\begin{tabular}{|c|c|c|c|}
\hline Produto & Qtde Produzida & UEP & Total de UEP \\
\hline Queijo mussarela & 1142 & 1,00000 & 1142 \\
\hline
\end{tabular}

Agora para se estabelecer quanto custa o produto para ser fabricado, é necessário calcular o valor em $\mathrm{R} \$$ da UEP. Esse valor é determinado através da divisão do custo de transformação total (em $R \$$ ) pela quantidade de UEPs fabricadas no período, conforme evidenciado na Tabela 8.

Os custos referentes à matéria-prima e embalagens consumidas, foram excluídos para determinação do valor em UEP. Para o cálculo do custo total (em $R \$$ ) do produto, basta acrescentar esses valores.

Tabela 8 - Custo do produto

\begin{tabular}{|c|c|c|c|}
\hline Produto & $\begin{array}{c}\text { Custos } \\
\text { Transformação } \\
\mathbf{R} \mathbf{\$}\end{array}$ & Total de UEP & Custo em R\$ \\
\hline Queijo mussarela & 935,5 & 1142 & 0,8192 \\
\hline
\end{tabular}

\section{CONSIDERAÇÕES FINAIS}

Este estudo teve por objetivo verificar a aplicabilidade do método da Unidade de Esforço de Produção - UEP na linha de produção de uma indústria de laticínios, considerando que a sua contribuição não está apenas na constatação da aplicabilidade 
Unidade de Esforço de Produção (UEP) como Método de Custeio: Implantação de Modelo em uma Indústria de Laticínios

Daiane Cambruzzi, Fábio Vianei Balen, João Francisco Morozini

do método no segmento industrial, mas, sim, na sua aplicação em uma situação específica.

O foco principal do método não é encontrar o custo de fabricação dos produtos, mas o esforço que a indústria realiza para produzi-los, ou seja, o método não se resume ao custeio de produtos. Nesse sentido, Kliemann Neto (1991) adverte que a UEP serve de base tanto para a implementação de sistemas de custos precisos e eficazes, quanto para a realização das atividades de planejamento e programação da produção e controle de eficiência. Este motivo levou ao estudo e utilização desse método junto a uma indústria de laticínios.

Quanto aos aspectos da aplicação do método UEP, a partir desse estudo, podese constatar que são vários os benefícios inerentes ao método. É por meio dele que se tem o conhecimento de todos os processos necessários para a transformação de uma matéria-prima em um produto acabado, inclusive com as respectivas quantidades que cada processo necessita para a fabricação do produto.

O método UEP mensura todos os esforços despendidos durante o processo de transformação da matéria prima pelos postos operativos, tais como: folha de pagamento; consumo de energia elétrica; e depreciação de equipamentos utilizados na produção, o que, conseqüentemente, permite que sejam feitas análise dos esforços de cada posto operativo, medindo assim seu desempenho e permitindo melhorias contínuas do sistema produtivo.

As dificuldades encontradas quando da utilização do Método das UEPs é que este necessita de um detalhamento para a sua implantação. É necessário especificar os postos operativos de forma clara para a obtenção de informações extra-contábeis como, por exemplo, a depreciação, ou seja, é preciso que se construa um sistema de informações que permita que os custos sejam atribuídos aos postos operativos da maneira mais correta possível, permitindo uma correta determinação das UEP/h de cada posto operativo. Além disso, a utilização do Método das UEPs, de acordo com Antunes Junior (1998), requer que se conheça previamente a fábrica e os princípios básicos do próprio método. 
Unidade de Esforço de Produção (UEP) como Método de Custeio: Implantação de Modelo em uma Indústria de Laticínios

Daiane Cambruzzi, Fábio Vianei Balen, João Francisco Morozini

Fernandes (2003, p.162) reafirma que "para o Método das UEPs uma característica imprescindível é que existam profissionais conhecedores de fábrica e, portanto, capazes de analisar eficazmente a estrutura produtiva da mesma". Ainda que o método UEP possua vantagens e limitações, como todos os métodos atualmente utilizados, conclui-se que o mesmo demonstra ser o método mais adequado à empresa em estudo. Isso porque o método UEP vem suprir as necessidades informativas da empresa, a saber: controle sobre seus postos operativos e custo de transformação dos produtos fabricados, uma vez que a forma de controle utilizada abrange quase que exclusivamente o consumo de matéria prima.

Com a utilização do método UEP a empresa passa a contar com a estimativa do custo total do produto, uma vez que este possibilita calcular o custo de transformação do produto fabricado, somando-se ao custo da matéria prima consumida e embalagens. Essa informação e outras que esse método pode gerar proporcionam aos gestores da empresa uma maior segurança quanto à determinação da rentabilidade de seu produto vendido, além de outras informações gerenciais.

Para indústrias que atuam no segmento de lacticínios, esse fato pode representar um diferencial significativo. Isso porque no mercado de laticínios percebese uma grande disputa não só na venda dos produtos industrializados, como também na compra da matéria prima. Sendo assim, há a necessidade de seguir os preços de compra e venda que o mercado impõe. E diante desses fatos, nota-se que a empresa precisa de um acompanhamento efetivo sobre o seu processo de produção.

\section{REFERÊNCIAS}

ALLORA, Franz; ALLORA, Valério. (1995). UP: unidade de medida da produção para custos e controles gerenciais das fabricações. (1 ed.). São Paulo: Pioneira.

ANTUNES JUNIOR, José Antonio Vale. (1988). Fundamentação do método das unidades de esforço de produção. (Dissertação de Mestrado). UFSC, Florianópolis.

BORNIA, Antônio César. A Fusão de Postos Operativos no Método da Unidade de Esforço de Produção. Disponível em: http://libdigi.unicamp.br/document/?view=44. Acesso em: abri/2008. 
Unidade de Esforço de Produção (UEP) como Método de Custeio: Implantação de Modelo em uma Indústria de Laticínios

Daiane Cambruzzi, Fábio Vianei Balen, João Francisco Morozini

BORNIA, Antonio C. (2002). Análise Gerencial de Custos. Porto Alegre: Bookman.

BORNIA, Antônio C. (1995). Mensuração das Perdas dos Processos Produtivos: Uma abordagem metodológica de controle interno. (Tese de Doutorado). UFSC, Florianópolis.

CORAL, Eliza. (1996). Avaliação e gerenciamento dos custos da não-qualidade, Dissertação de Mestrado, UFSC, Florianópolis. Disponível em: http://teses.eps.ufsc.br/defesa/pdf/9780.pdf. Acesso em: abril/2008.

CORONETTI, Jucimar; BEUREN, Ilse M.; SOUZA, Marco A. B. (2003). Os Métodos de Custeio Utilizados nas Maiores Indústrias de Santa Catarina. In: Congresso Brasileiro de Custos, 10, Vitória (Espírito Santo). Anais...Vitória: ABC. CD-ROM.

DINIZ, Josedilton A. (2004). O método das unidades de esforço de produção (UEP) como instrumento diferencial diante da competitividade industrial. In: Congresso Brasileiro de Custos, 11, Porto Seguro (Bahia). Anais. Porto Seguro: ABC. CD-ROM.

FARIAS, Viviane M.; LEMBECK, Marluce. (2005). Aplicação do método de custeio UEP em pequena empresa industrial. In: Congresso Internacional de Custos, 9, Florianópolis. Anais...Florianópolis: ABC. CD-ROM.

FERNANDES, Joaquim de Sousa. (2003). Sistematização de uma abordagem da medição de uma produção diversificada e seus desempenhos num ambiente industrial pelo método das unidades de esforço de produção - UEPs. (Dissertação de Mestrado). UFRGS, Porto Alegre. Disponível em: http://volpi.ea.ufrgs.br/teses_e_dissertacoes/td/000661.pdf . Acesso em abr./2008.

GIL, Antonio Carlos. (2002). Como elaborar projetos de pesquisa. (4 ed.). São Paulo: Atlas.

IAROZINSKI NETO, Alfredo. (1989). A Gestão Industrial através do método das unidades de esforço de produção. (Dissertação de Mestrado). UFSC, Florianópolis. Disponível em: http://teses.eps.ufsc.br/defesa/pdf/110.pdf. Acesso em: abril/2008.

LEMBECK, Marluce; WERNKE, Rodney. (2008). Aplicação do método UEP em uma indústria de produtos descartáveis de plástico. CRC-RS. Porto Alegre, n. 132, p. 18-33, abril.

MARTINS, Eliseu. (2003). Contabilidade de Custos. (9 ed.). São Paulo: Atlas.

MORAIS, José Claudiomar et. al. (1986). Sistema de informação. Revista Brasileira de Contabilidade. Rio de Janeiro, v. 27, n. 59, p. 9-12, out/dez. 
MUNARETTO, Lorimar F.; DIEDRICH, Márcia. (2005). Custeio Abc (Activity-Based Costing) Integrado Ao Custeio Variável: estudo de Caso em indústria de embalagem para presentes. In: Congresso Internacional de Custos, 9, Florianópolis. Anais...Florianópolis: ABC. CD-ROM.

PEREIRA, Fernando S.; REBELATO, Daisy A. N.; TACHIBANA, Wilson K. (2000). Revisitando o método das unidades de esforço de produção (UEP's): algumas considerações quanto a sua eficiência e eficácia como instrumento de gestão. In: Congresso Brasileiro de Custos, 7, Recife. Anais...Recife: ABC. CD-ROM.

SAKAMOTO, Frederico Tadashi C. (2003). Melhoramento nas ferramentas de gestão de custo e produção: implantação, sistematização e utilização da UP, unidade de produção, na Seara Alimentos S.A. In: Congresso del Instituto Internacional de Costos, 8, 2003, Punta del Este (Uruguai). Anais...Punta del Este (Uruguai): IIC. CD-ROM.

WERNKE, Rodney. (2005). Análise de custos e preços de venda: ênfase em aplicações e casos nacionais. São Paulo: Saraiva.

WERNKE, Rodney; MORAES, Lívia C.; CARDOSO, Thaynã B. (2004). Cálculo do custo de fabricação em empresa do segmento de costura industrial terceirizada (facção): estudo de caso aplicando o método UEP. In: Congresso Brasileiro de Custos, 11, Porto Seguro (Bahia). Anais. Porto Seguro: ABC. CD-ROM.

Data de Submissão: 06/01/2009

Data de Aceite: 28/04/2009 